\title{
Kentsel Dönüşüm Kapsamında Çok Katlı Betonarme Bir Binanın Deprem Performansının Değerlendirilmesi
}

\author{
Seismic Performance Assessment of a Multi-Story Reinforced Concrete Building in Urban \\ Transformation
}

\author{
Zeynep FIRAT ALEMDAR*a, Deniz CAYMAZER ${ }^{\mathrm{b}}$ \\ Yıldız Teknik Üniversitesi, İnşaat Fakültesi, Inşaat Mühendisliği Bölümü, 34220, Esenler, İstanbul
}

• Geliş tarihi / Received: 20.12.2017 • Düzeltilerek geliş tarihi / Received in revised form: 09.03.2018 • Kabul tarihi / Accepted: 24.03 .2018

\section{Öz}

Türkiye, topraklarının \%92'lik bölümü deprem bölgesinde yer alan bir ülkedir. Kontrolsüz kentleşme nedeniyle daha önce yaşanan depremlerde can ve mal kaybının meydana gelmesi ve mühendislik hizmetlerinden yoksun bina sayısının çok fazla olması kentsel dönüşüm konusunu gündeme getirmiştir. Bu kapsamda, Türkiye'de yürürlüğe giren 16.05.2012 Tarih ve 6306 Sayılı Afet Riski Taşıyan Alanların Dönüştürülmesi Hakkında Kanun’da öngörülen esaslar ile kentsel dönüşüm projesi kapsamında betonarme bir bina ele alınmıştır. İncelenen bina Deprem Bölgelerinde Yapılan Binalar Hakkında Yönetmelik (DBYBHY) 2007'de belirtilen Zaman Tanım Alanında Doğrusal Olmayan Hesap Yöntemi ile analiz edilmiş ve taşıyıcı sistem elemanlarının performansı yönetmelikte tanımlanan kurallara göre belirlenmiştir. Binanın deprem performansı taşıyıcı elemanlarda elde edilen hasar durumlarına göre saptanmış ve binanın depreme dayanıklı olup olmadığı belirlenmiş̧ir.

Anahtar kelimeler: Betonarme bina, Kentsel dönüşüm, Sismik performans, Zaman tanım alanında doğrusal olmayan analiz

\begin{abstract}
Turkey is a country whose land is $\% 92$ comprised of earthquake zones. Because of the loss of life and property during the previous earthquakes happened due to unplanned urbanization and the high number of buildings without engineering services, urban renewal was carried to the agenda. In this context, the seismic performance of a multi-story reinforced concrete building within the scope of an urban renewal project was evaluated according to the Urban Renewal Law passed in Turkey in May 2012. The building was analyzed using the Nonlinear Dynamic Time History Analysis according to the Turkish Earthquake Code 2007 (TEC-2007) and the seismic performance of structural members was determined according to the requirements in the code. The global performance level of the building was obtained regarding the damage levels of the members and it was decided that whether or not the building was safe under the earthquake loads.
\end{abstract}

Keywords: Reinforced concrete building, Urban renewal, Seismic performance, Nonlinear time history analysis

\footnotetext{
*a Zeynep FIRAT ALEMDAR; zalemdar@yildiz.edu.tr; Tel: (0212) 38351 42; orcid.org/0000-0002-0793-8582

${ }^{\mathrm{b}}$ orcid.org/0000-0003-0041-7810
} 


\section{Giriş}

Performansa dayalı deprem analizlerinde, araştırmacılar doğrusal olmayan davranışları göz önüne alarak yapılardaki yük ve deplesman kapasite seviyelerini ve sismik talebi tahmin etmek için basit ve pratik yöntemler geliştirmeye çalışmışlardır (Chopra, 2004). Mevcut betonarme binaların deprem performansını değerlendirmek amaciyla, doğrusal olmayan statik itme ve zaman tanım alanında dinamik analizler kullanılmıştır (Scawthorn ve Johnson, 2000; Adalier ve Aydingun, 2001; Sezen vd., 2003; Kalkan ve Kunnath, 2007; Sadjadi vd., 2007). Doğrusal olmayan zaman tanım alanında dinamik analizin karmaşıklığı ve uygulamasının zor olması nedeni ile doğrusal olmayan statik metotlar tercih edilmektedir (Pinho ve Antoniou, 2005). Ancak; doğrusal olmayan statik yöntem, yapının birinci modunu dikkate almakta ve düşük ile orta yükseklikteki düzenli yapılarda uygulanabilmektedir. Geleneksel doğrusal olmayan statik metot, düzensiz plana sahip yüksek katlı yapıların üst katlarının sismik taleplerini büyük ölçüde göz ardı etmektedir; çünkü bu yöntemde yapının yüksek modların analize katkıları düşünülmemektedir (Poursha, 2008). Bu çalışmada, incelenen bina simetrik olmayan plana sahip olduğundan DBYBHY (2007) yönetmeliğinde tanımlanan A1 tipi burulma düzensizliği şartını sağlamaktadır. Bu nedenler, yapı Zaman Tanım Alanında Doğrusal Olmayan Hesap Yöntemi kullanılarak analiz edilecek ve depremselliği incelenecektir.

Şahin (2010) çalışmasında, DBYBHY'de (2007) tanımlanmış olan doğrusal elastik olmayan hesap yöntemlerinden Artımsal Eşdeğer Deprem Yükü Yöntemi ve Zaman Tanım Alanında Hesap Yöntemlerini kullanarak performans analizleri yapmıştır. Analizler sonucunda elde edilen sonuçlara göre Türk Deprem Yönetmeliği Bölüm 7'de tanımlanan performans düzeyleri karşılaştırılmıştır. Artımsal Eşdeğer Deprem Yükü Yöntemi ile analiz yapılabilmesi için yönetmelikte tanımlanan koşulların sağlanması gerekmektedir. Yöntemin uygulanabilmesi için burulma düzensizlikleri ve kat sayıları birbirinden farklı 4 bina incelenmiştir. Zaman Tanım Alanında Hesap Yöntemi'nin sonuçları doğru kabul edilerek uygulanan yöntemlerden elde edilen kesit hasar durumları ve bina tepe yer değiştirme sonuçları karşılaştırılmıştır. Yönetmelikte belirtilen kurallara uygun olan yapılarda analiz sonuçlarının birbirine yakın olduğu gözlemlenmiştir. Yapının burulma düzensizliğinin artması veya etkin kütle oranının azalması durumunda sonuçların farklılaştığı saptanmıştır.

Karabulut (2011) yaptığı çalışmada, DBYBHY (2007) ve TS500 (2000) yönetmelikleri kurallarına göre tasarlanmış üç farklı betonarme binay1 incelemiştir. Binaların performans durumları DBYBHY (2007) ve FEMA 440 (2005) yönetmeliklerinde verilen Doğrusal Olmayan Statik İtme Analizi yöntemleriyle ve ayrıca DBYBHY'de (2007) tanımlanan Doğrusal Olmayan Dinamik Analiz Yöntemi ile belirlenmiştir. Her iki yönteminde uygulandığı binalarda ortalama tepe yer değiştirme değerleri ve katlara göre plastikleşen kiriş ve kolon sayıları irdelenmiştir. Doğrusal olmayan statik analizler ile bulunan en üst kattaki yer değiştirme değerleri birbirine yakın sonuçlar vermesine rağmen, taban kesme kuvveti değerleri farklılık göstermektedir. Duan ve Hueste (2012) mevcut Çin deprem yönetmeliği kurallarına göre inşa edilmiş çok katlı bir betonarme yapının sismik performansını araştırmışlardır. Yapı doğrusal olmayan statik ve dinamik analiz metotları kullanılarak incelenmiştir. Ele alınan yapının mevcut yönetmeliğin gerektirdiği elastik olmayan davranış ve göreli kat ötelemeleri sınır değerlerini sağladığı görülmüştür.

Kueht ve Hueste (2009), Amerika Birleşik Devletlerinin orta eyaletlerine ait mevcut bina yönetmeliklerine (2003 Uluslararas1 Yap1 Yönetmeliği (IBC) (2003), yerel Memphis eyaleti değişiklikleri ile birlikte 2003 IBC (2005) ve 1999 Standart Yap1 Yönetmeliği (SBCCI 1999)) göre ayrı ayrı tasarlanmış dört katlı tipik bir betonarme binanın nümerik modelini kurmuşlardır. Uluslararas1 IBC-2003 ve SBCCI-1999 yönetmeliklerinde binaların depreme karşı tasarımlarında yapı elemanlarında özel detaylandırmalar gerekmektedir. Fakat Memphis eyaleti için düzenlenen 2003 IBC (2005) yönetmeliğinde daha az deprem tasarım detayları mevcuttur. Binaya 50 yıl içinde aşılma olasıllığ $\% 10$ ve $\% 2$ olan iki farklı deprem düzeyleri uygulanmıştır. Binanın sismik performansı, statik itme analizleri ve yapay deprem hareketleri kullanılarak dinamik doğrusal olmayan analizler yapılarak belirlenmiştir. Analitik sonuçlar, Uluslararas1 IBC-2003 ve SBCCI-1999 yönetmeliklerinde tanımlanan özel sismik detaylandırmaların orta Amerika'daki küçük ve orta katlı binaların deprem performansında önemli bir iyileşme sağlayabileceğini göstermiştir.

Atmaca (2013) çalışmasında DBYBHY (2007) yönetmeliğinde tanımlanan Artımsal Eşdeğer 
Deprem Yükü Yöntemini kullanarak 8 katlı betonarme binanın performansını belirlemiş ve yapı elemanlarının güçlendirilmesini incelemiştir. $\mathrm{Bu}$ güçlendirme yöntemleri yapısal ve ekonomik olarak incelenerek en uygun teknik seçilmiştir. İncelenen betonarme binanın performans1 belirlenirken taşıyıcı sistem elemanları kendi içinde ve kat bazında değerlendirilmiş ve en kötü durumdaki performans seviyesi dikkate alınarak güçlendirme kararı verilmiştir.

\section{2. İncelenen Çok Katlı Betonarme Yapı}

Bu çalışmada, Doğrusal Olmayan Dinamik Hesap Yöntemi ile performansı belirlenmek istenen yap1; İstanbul ili, Zeytinburnu İlçesinde bulunan 1995 yılında inşa edilmiş, betonarme çerçeve sistemli 6 katl $(2$ Bodrum kat + Zemin kat +3 Normal kat) bir yapıdır. İncelenen yapının 6306 Sayılı Kanun kapsaminda belirlenen kurallara göre deprem performansı incelenerek kullanımının riskli olup olmadığının belirlenmesi için mimari ve statik projeleri Zeytinburnu Belediyesi İmar ve Şehircilik Müdürlüğü arşivinden temin edilmiştir. Binanın bulunduğu zemin yerel zemin sınıfi tanımına göre Z2'dir ve bina 1. Deprem bölgesindedir. $\mathrm{Bu}$ betonarme bina 1975 Türk Deprem Yönetmeliğine göre inşa edilmiştir. Yerinde yapilan incelemede bina geometrisinin projesine uygun olduğu görülmüştür. Binada bulunan tipik kiriş ve kolon kesitleri Şekil 1'de verilmiştir. Kesitlerdeki paspayları kolonlar için $2.5 \mathrm{~cm}$ kirişler için $2 \mathrm{~cm}$ 'dir. Binanın temel oturumu $67 \mathrm{~m}^{2}$ olup toplam inşaat alanı 472.5 $\mathrm{m}^{2}$ 'dir. Konut olarak kullanilan bina tekil temel sistemine sahip olup döşeme sistemi plak döşemedir. Bodrum katların çevresi rijit betonarme perdelerle çevrilmiştir.

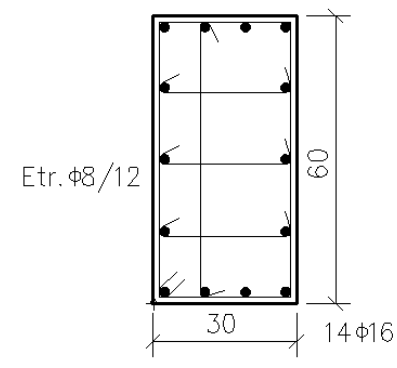

(a)

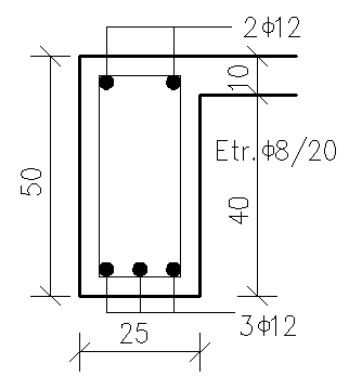

(b)
Şekil 1. Tipik (a) kolon ve (b) kiriş kesitleri

\subsection{Malzeme Özelliklerinin Belirlenmesi}

İlgili yasa gereği mevcut donatı düzenini belirlemek için kritik katta sıyırma ve röntgen adı verilen tahribatsız yöntemler ile tespitler yapılmıştır. DBYBHY (2007) yönetmeliğinde rijitliği diğer katlara oranla çok küçük olan veya yanal ötelenmesi zemin tarafindan tutulmamış olan en alttaki bina katı kritik kat olarak kabul edildiğinden, incelenen binada kritik kat binanın zemin katı olarak kabul edilmiştir. Tahribatsız yöntemler sonucunda, binada kullanılan donatı çeliği sınıfının S220 olduğu ve donatı düzeninin projesine uygun olduğu görülmüştür (Şekil 2).

İncelenen binadaki beton dayanımının belirlenmesi amaciyla Türk Deprem Yönetmeliğindeki kurallara uygun olarak binanın kritik kat kolon ve perdelerinden en az 10 elemanda tahribatsız yöntem (Schmidt çekici) uygulanarak ölçümler yapılmış (Şekil 3) ve en düşük sonucun elde edildiği 5 taşıyıcı elemandan beton numuneler alınmıştır (Şekil 4). İlgili yasa gereği kat oturum alanı $400 \mathrm{~m}^{2}$ 'ye kadar olan binalardan 5 adet karot numune alınmaktadır. Çalışılan binanın kat oturum alanı $67 \quad \mathrm{~m}^{2}$ olduğundan kritik katta bulunan kolonlardan 5 adet numune alınmış ve laboratuvar ortamında test edilmiştir. Deney sonucunda mevcut betonun ortalama dayanımının $16.1 \mathrm{MPa}$ olduğu saptanmıştır (Tablo 1). Ayrıca, yerinde yapılan incelemelerde taşıyıcı sistem kesitlerinin projesine uygun olduğu tespit edilmiştir.

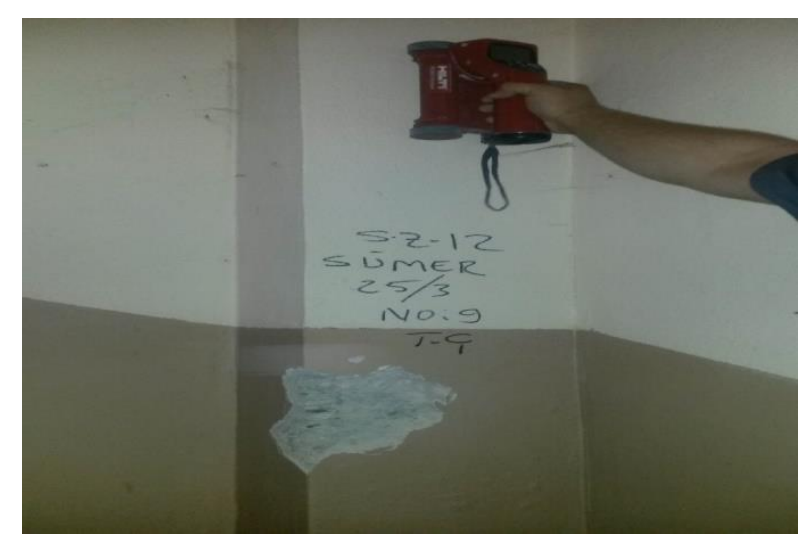

Şekil 2. Okuma yöntemiyle mevcut donatı tespiti

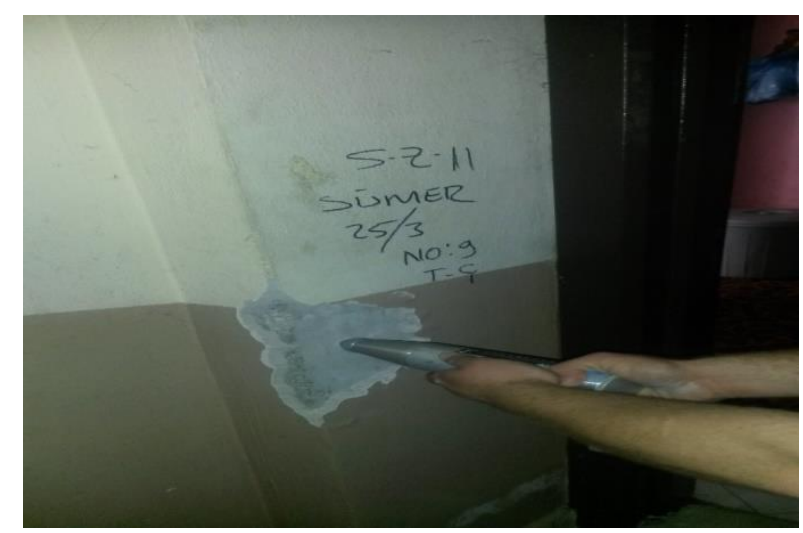

Şekil 3. Tahribatsız yöntemle beton dayanımının ölçülmesi 


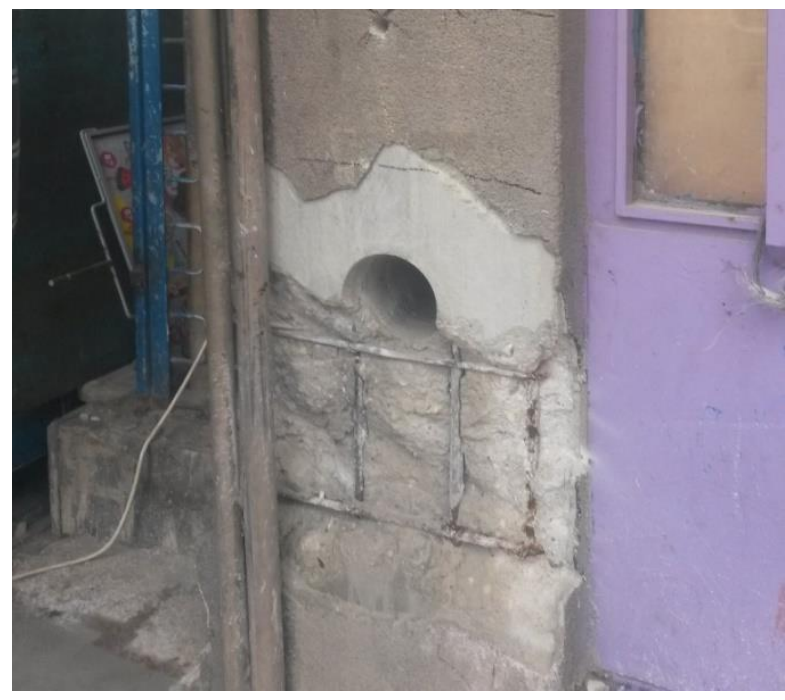

Şekil 4. Beton numunesi alınmış ve sıyırma yöntemiyle donatı tespiti yapılmış taşıyıcı eleman

\subsection{Yapının Periyodunun Yerinde Tespiti}

Binanın doğal titreşim periyodunun yerinde ölçülebilmesi için ivmeölçerlerle ölçümler yapılmıştır. Bina içinde en tepe ve en alt noktalara ivmeölçerler yerleştirilerek binanın periyodu yerinde ve üzerinde hareketli yük olmadan ölçülmüştür (Şekil 5). Ölçüm cihazları üç eksenli olup, kuvvet dengelemelidir. İvme kayıt bandı 0$100 \mathrm{~Hz}$ arasında ve ivme çıkış hassasiyeti $2 \mathrm{~g}$ 'dir.

\section{Yapının Modellenmesi}

İncelenen betonarme yap1 SAP2000 sonlu elemanlar programında (2015) yerinde alınan karot numunelerin ve donatı çeliğinin malzeme özellikleri kullanılarak 3 boyutlu olarak modellenmiştir (Şekil 6).

Tablo 1. Sertleşmiş beton basınç dayanımı raporu

\begin{tabular}{|l|l|l|}
\hline \multicolumn{2}{|l|}{ Beton Basınç Dayanım Test Raporu } \\
\hline Adet/Tip & $5 /$ Silindir \\
\hline Boyut (mm) & 90 \\
\hline Deney Sonuçları & Taşıyıcı Elemanın Adı & Basınç Mukavemeti(N/mm²-MPa) \\
\hline 1 & Zemin Kat Kolon SZ14 & 16.6 \\
\hline 2 & Zemin Kat Kolon SZ 15 & 18.1 \\
\hline 3 & Zemin Kat Kolon SZ 16 & 24.1 \\
\hline 4 & Zemin Kat Kolon SZ 17 & 12.8 \\
\hline 5 & Zemin Kat Kolon SZ 18 & 9.0 \\
\hline Ortalama Karot Basınç Dayanımı & & $\mathbf{1 6 . 1}$ \\
\hline
\end{tabular}

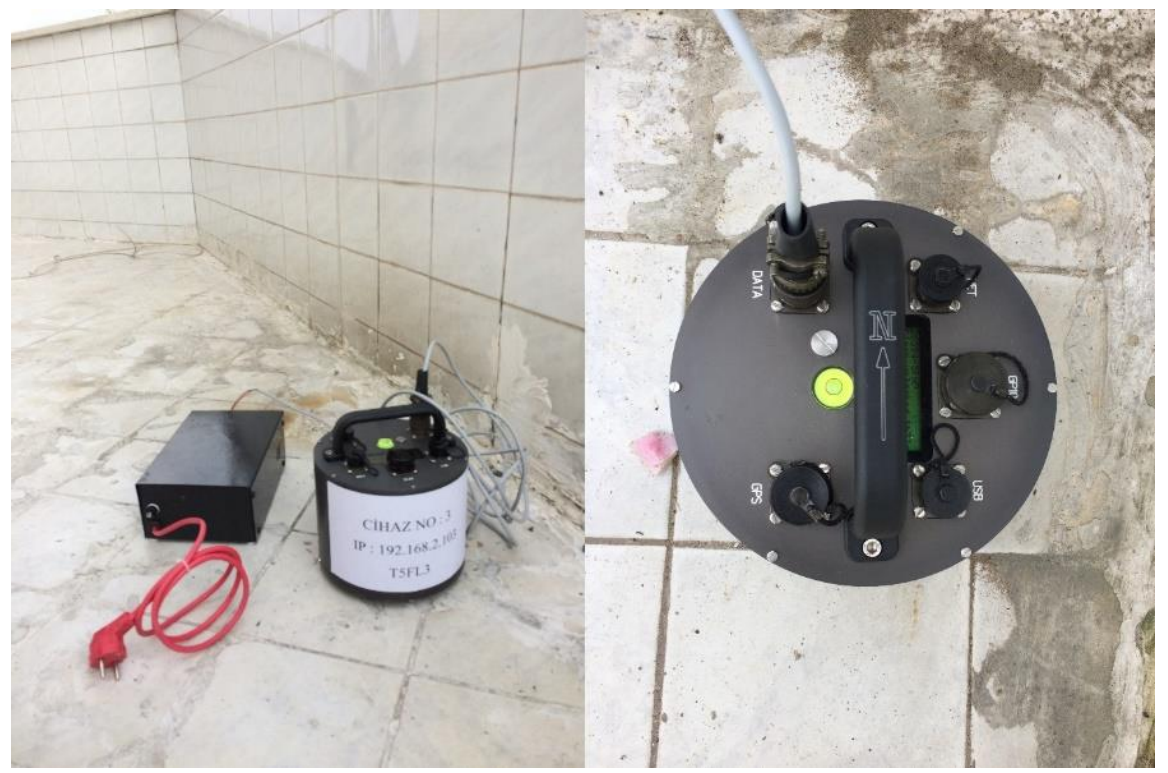

Şekil 5. Binada ivmeölçerlerle tespit 


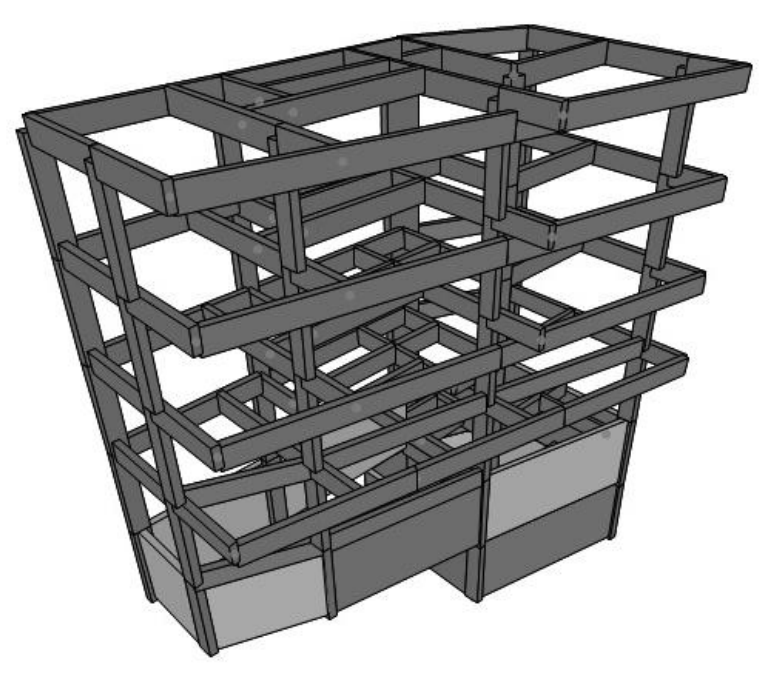

Şekil 6. Yapının 3 boyutlu SAP2000 modeli

Kolon, kiriş ve perde elemanlarının kesit ve aks aralıkları yapılan röleve çalışmasında projesine uygun olarak tespit edildiğinden projedeki ölçüler kullanılarak tanımlanmıştır. Kiriş elemanlardaki ölü ve hareketli yükler tanımlanmıştır. Döşemeler ise modele eklenmeden döşeme öz yükü ve üzerindeki hareketli yükler kirişlere aktarılmıştır. Her kat seviyesinde rijit diyaframlar tanımlanmış, etkin eğilme rijitlikleri ve taşıyıcı eleman uçlarındaki mafsallar DBYBHY'de (2007) belirtilen esaslara göre çalışan doğrultudaki kesit boyutunun yarısına eşit olarak hesaplanmıştır (Caymazer, 2017).

Sonlu elemanlar modelinde yapının her iki doğrultudaki hakim periyot değerleri ölü yükler etkisi altında $T_{1}=0.35$ ve $T_{2}=0.34$ saniye olarak hesaplanmıştır. İvmeölçerlerle binada yapılan ölçümlerde elde edilen ivme değerleri MATLAB programında (2000) dönüştürülerek yapının hakim periyotlar1 $\mathrm{T}_{1}=0.28$ ve $\mathrm{T}_{2}=0.24$ saniye olarak hesaplanmıştır. Gerçek malzeme ve proje verilerinin kullanilmasi durumunda sonlu elemanlar modeli sonuçları ile ivmeölçer sonuçlarının birbirine yakın olduğu gözlemlenmiştir.

\section{Doğrusal Olmayan Dinamik Hesap Yönteminin Uygulanması}

Deprem bölgelerinde inşa edilen tüm bina ve bina türü yapıların uygulanan deprem yükleri altında performanslarının incelenmesi için DBYBHY'de (2007) hesap yöntemleri tanımlanmıştır. $\mathrm{Bu}$ metotlar doğrusal elastik ve doğrusal elastik olmayan hesap yöntemleri olarak iki kısımdan oluşmaktadır. Doğrusal elastik olmayan yöntemler; Artımsal Eşdeğer Deprem Yükü Yöntemi, Artımsal Mod Birleştirme Yöntemi ve
Zaman Tanım Alanında Hesap Yöntemi (Dinamik Analiz) olarak üçe ayrılmaktadır (DBYBHY, 2007). Bu çalışmada Doğrusal Olmayan Dinamik Analiz Yöntemi kullanılacak ve ele alınan yapının deprem performansı belirlenecektir.

Doğrusal Olmayan Dinamik Analiz Yöntemi'nde yapıya uygulanacak kaydedilmiş yer hareketleri DBYBHY'de (2007) belirtilen kurallara uygun olarak seçilmiştir (Tablo 2). Bu deprem kayıtları yapının $\mathrm{X}$ ve $\mathrm{Y}$ doğrultularında uygulanmıştır. 1999 Kocaeli depremine ait kuzey-güney ve doğubatı doğrultularında kaydedilmiş ivme değerleri Şekil 7 ve 8'da gösterilmiştir. Seçilen üç deprem kaydı ile yapılan dinamik analiz sonuçları incelendiğinde, yapının 1999 Kocaeli depremi altında elde edilen sonuçlarının en uygunsuz koşulları verdiği görülmüş ve binadaki şekil değiştirme ve kesme kuvveti istemleri bu deprem analizinden hesaplanmıştır.

\subsection{Kolon ve Kirişlerin Plastik Mafsal Özelliklerinin Belirlenmesi}

İncelenen binadaki tüm kolon ve kiriş elemanlarının mesnet bölgelerindeki kesit özellikleri XTRACT (2004) programında tanımlanmış ve kesit analizleri yapılmıştır. Binada mevcut beton malzemenin dayanım özellikleri Mander sargilı ve sargisiz beton modelleri (Mander vd., 1988) kullanılarak, donatı çeliği malzeme özellikleri ise pekleşme etkisi dikkate alınarak programa tanımlanmıştır. Doğrusal olmayan kesit davranışlarını temsil eden plastik mafsal özellikleri kesitlerin moment-eğrilik ilişkilerinden ve 3 boyutlu etkileşim yüzeylerinden yararlanılarak SAP2000 programında tüm kolon ve kiriş kesitlerine eklenmiştir.

\subsection{Etkin Eğilme Rijitlikleri Hesabı}

DBYBHY(2007) yönetmelik kurallarına göre Doğrusal Olmayan Dinamik Analiz Yöntemi uygulanırken kolon, kiriş ve perde elemanlarında etkin eğilme rijitlik oranlarının hesaplanması ve ayrica sonlu elemanlar modelinde bu rijitlik değerlerinin dikkate alınması gerekmektedir. Eğilme etkisine maruz betonarme yap1 elemanların akma meydana gelmeden önceki doğrusal davranışlarının sonlu elemanlar modeline tanımlanması çatlamış kesite ait eğilme rijitliklerinin kullanılması ile mümkündür. Etkin eğilme rijitlik oranları yönetmelikte belirtilmiş olan esaslara uygun olarak hesaplanmış ve SAP2000 modelinde gerekli düzenlemeler yapılmıştır. Binadaki bazı kolonlar için elde edilmiş etkin eğilme rijitlik değerleri Tablo 3 'de verilmiştir. 
Tablo 2. Performans analizinde kullanılan deprem kayıtları

SEÇİLEN DEPREM KAYITLARI

\begin{tabular}{|lllllll}
\hline No & Deprem Adı & Merkez Üssü & Tarih/Saat & $\begin{array}{c}\text { Büyüklük } \\
\text { (Mw) }\end{array}$ & $\begin{array}{c}\text { İme Kaydının Süresi/Kayıt } \\
\text { Aralı̆ğ } \\
\text { (sn) }\end{array}$ \\
\hline 1 & Kocaeli & İzmit/Türkiye & 17 Ağustos 1999/03:01 & 7.6 & $40 / 0.01$ & \\
\hline 2 & Düzce & Düzce/Türkiye & 12 Kasım 1999/18:57 & 7.2 & $40 / 0.01$ & \\
\hline 3 & Bingöl & Bingöl/Türkiye & 1 Mayıs 1999/03:27 & 6.4 & $17 / 0.01$ & \\
\hline
\end{tabular}

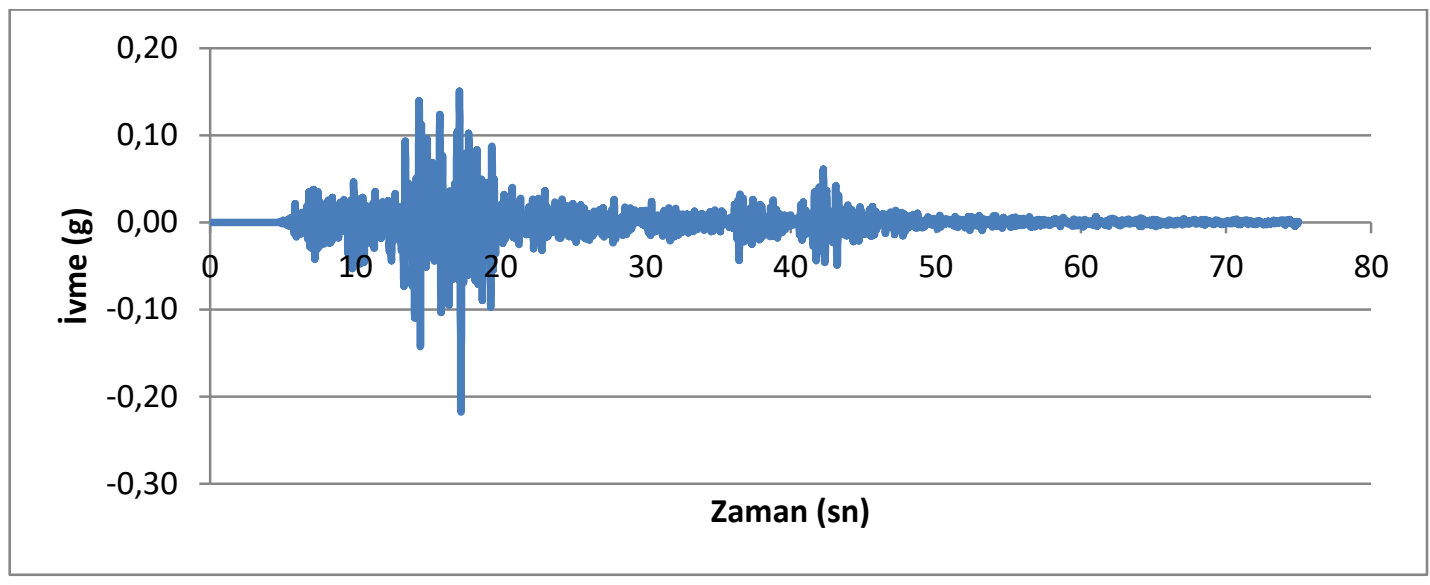

Şekil 7. Kocaeli depremi kuzey-güney doğrultusu ivme kaydı.

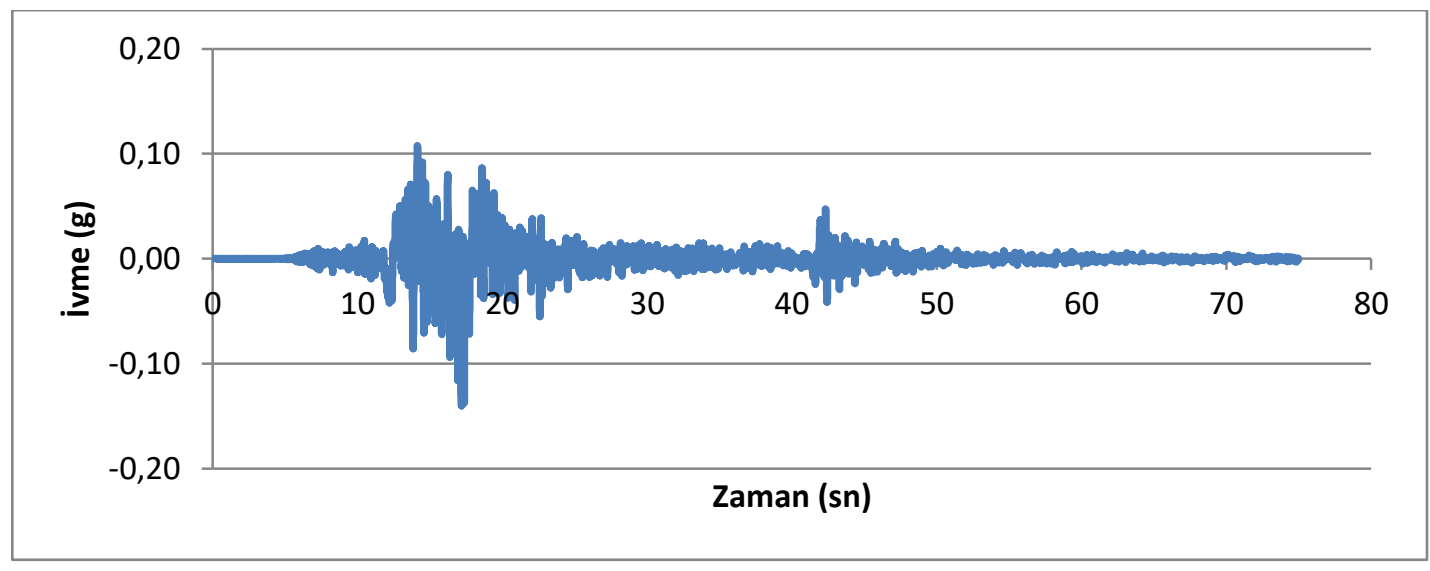

Şekil 8. Kocaeli depremi doğu-batı doğrultusu ivme kaydı.

Tablo 3. Etkin eğilme rijitlik oranları

\begin{tabular}{|l|l|l|l|l|l|}
\hline $\begin{array}{l}\text { Kolon } \\
\text { No }\end{array}$ & $N_{D}$ & $A_{c}$ & $f_{c m}$ & $(E I)_{\mathrm{o}}$ & $(\boldsymbol{E I})_{\mathbf{e}} /(\mathbf{E I})_{\mathbf{o}}$ \\
\hline 1 & -20.429 & 0.125 & 10500 & 0.0156 & $\mathbf{0 . 4}$ \\
\hline 2 & -627.775 & 0.25 & 10500 & 0.4783 & $\mathbf{0 . 8}$ \\
\hline 4 & -465.927 & 0.1 & 10500 & 0.4437 & $\mathbf{0 . 8}$ \\
\hline 5 & -299.269 & 0.1 & 10500 & 0.2850 & $\mathbf{0 . 6 4 6 7}$ \\
\hline 6 & -133.866 & 0.1 & 10500 & 0.1275 & $\mathbf{0 . 4 3 6 7}$ \\
\hline
\end{tabular}

\subsection{Betonarme Elemanlarin Kesit Birim Şekildeğiştirme Kapasiteleri}

Analizler sonunda binadaki betonarme elemanların kesitlerinde meydana gelen plastik eğrilik istemleri hesaplanmıştır. Kesit analizlerinden elde edilen moment-eğrilik ilişkileri yardımı ile kesitlerin eşdeğer akma eğrilik değerleri belirlenmiş ve sonlu elemanlar modelinden hesaplanan plastik eğrilik istemleri ile toplanarak kesitlerden talep edilen toplam eğrilik değerleri bulunmuştur. Daha sonra, betonarme 
yap1 elemanların beton ve donatı çeliğinde meydana gelen birim şekildeğiştirme değerleri moment-eğrilik ilişkilerinden hesaplanmıştır. Bu değerler DBYBHY'de (2007) verilmiş olan malzeme birim şekildeğiştirme sınır değerleri ile kiyaslanarak betonarme kesitlerdeki hasar durumlarına karar verilmiştir. Binada bulunan birer kiriş ve kolon elemanı için kesit düzeyinde performansin belirlenmesi Tablo 4'de örnek olarak açıklanmıştır.

Kesit hasar bölgeleri sünek davranış gösteren elemanlar için Minimum Hasar Bölgesi, Belirgin
Hasar Bölgesi, İleri Hasar Bölgesi ve Göçme Bölgesi olmak üzere dört gruba ayrılmaktadır (Şekil 9). Türk Deprem Yönetmeliğindeki tanımlamaya göre; Minimum Hasar Bölgesinde bulunan kesitler Minimum Hasar (MN) sınırını aşmayan (1. Bölge), Belirgin Hasar Bölgesindeki kesitler MN-Güvenlik Sınırı (GV) hasar sınırları arasında (2. Bölge), İleri Hasar Bölgesindeki kesitler GV-Göçme (GÇ) sınırları arasında (3. Bölge) ve Göçme Bölgesinde (4. Bölge) yer alan kesitler GÇ üst sınırını aşmış kesitlerdir.

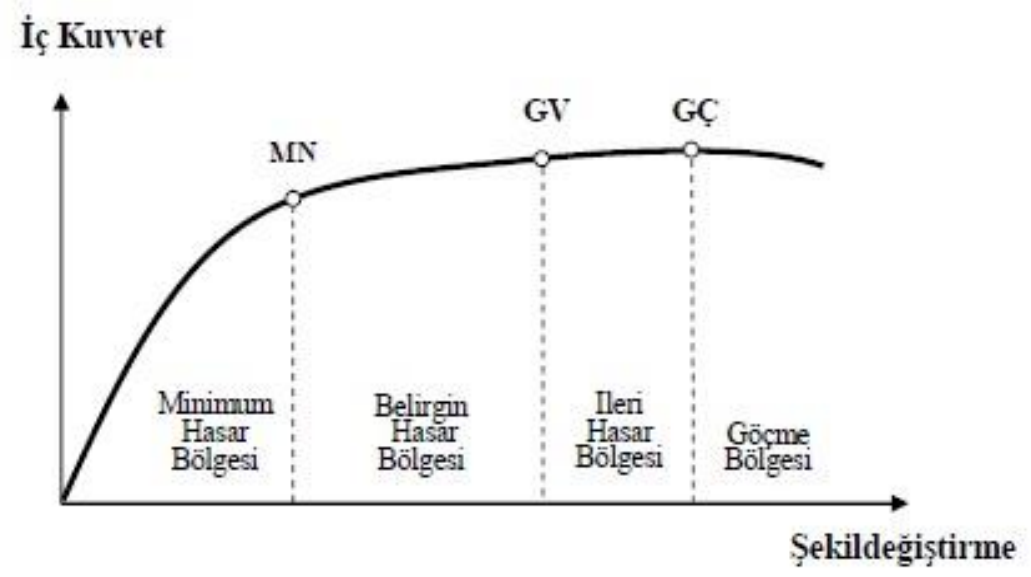

Şekil 9. Kesit hasar bölgeleri

Tablo 4. Kesit performans düzeyleri

\begin{tabular}{|c|c|c|c|c|c|c|c|c|c|c|c|}
\hline \multirow[t]{2}{*}{$\begin{array}{l}\text { Kesit } \\
\text { Adi } 1\end{array}$} & \multirow[t]{2}{*}{$\begin{array}{c}\text { Kesit } \\
\text { Boyutlar1 }\end{array}$} & $\begin{array}{l}\text { R3 Plastik } \\
\text { Dönme }\end{array}$ & \multirow[t]{2}{*}{$\begin{array}{l}\text { Maksimum } \\
\text { Dönme }\end{array}$} & $\begin{array}{c}\text { Mak. } \\
\text { Eğrilik }\end{array}$ & $\begin{array}{c}\text { Akma } \\
\text { Eğriliği }\end{array}$ & $\begin{array}{l}\text { Toplam } \\
\text { Egrrilik }\end{array}$ & $\begin{array}{c}\text { Çelik } \\
\text { Birim } \\
\text { Uzama }\end{array}$ & $\begin{array}{c}\text { Betonda } \\
\text { Birim } \\
\text { Uzama }\end{array}$ & \multirow[t]{2}{*}{$\begin{array}{c}\text { Çelik } \\
\text { Performans1 }\end{array}$} & \multirow[t]{2}{*}{$\begin{array}{c}\text { Beton } \\
\text { Performans1 }\end{array}$} & \multirow[t]{2}{*}{$\begin{array}{c}\text { Sonuç } \\
\text { Performans }\end{array}$} \\
\hline & & Radyan & & $\mathrm{rad} / \mathrm{m}$ & $\mathrm{rad} / \mathrm{m}$ & $\mathrm{rad} / \mathrm{m}$ & $\mathrm{m} / \mathrm{m}$ & $\mathrm{m} / \mathrm{m}$ & & & \\
\hline 5 & $\mathrm{~S} 40 \times 25$ & 0.001725 & \multirow{4}{*}{0.001725} & \multirow{4}{*}{0.0086} & \multirow{4}{*}{0.0084} & \multirow{4}{*}{0.017} & \multirow{4}{*}{0.0020} & \multirow{4}{*}{0.0029} & \multirow{4}{*}{$\varepsilon_{\mathrm{s}}<\mathrm{MN}$} & \multirow{4}{*}{$\varepsilon_{\mathrm{c}}<\mathrm{MN}$} & \multirow{4}{*}{$\varepsilon_{\mathrm{s}}<\mathrm{MN}$} \\
\hline 5 & $\mathrm{~S} 40 \times 25$ & 0.000412 & & & & & & & & & \\
\hline 5 & $S 40 \times 25$ & 0 & & & & & & & & & \\
\hline 5 & $\mathrm{~S} 40 \times 25$ & 0.001544 & & & & & & & & & \\
\hline 9 & $\mathrm{~K} 20 \times 60$ & 0.040065 & \multirow{4}{*}{0.044334} & \multirow{4}{*}{0.1480} & \multirow{4}{*}{0.0030} & \multirow{4}{*}{0.151} & \multirow{4}{*}{0.0077} & \multirow{4}{*}{0.0081} & \multirow{4}{*}{$\varepsilon_{\mathrm{s}}<\mathrm{MN}$} & \multirow{4}{*}{$\mathrm{MN}<\varepsilon_{\mathrm{c}}<\mathrm{GV}$} & \multirow{4}{*}{$\mathrm{IO}<\varepsilon<\mathrm{GV}$} \\
\hline 9 & $\mathrm{~K} 20 \times 60$ & 0 & & & & & & & & & \\
\hline 9 & K20x60 & 0.044334 & & & & & & & & & \\
\hline 9 & $\mathrm{~K} 20 \times 60$ & 0 & & & & & & & & & \\
\hline
\end{tabular}

\subsection{Kesme Kuvveti Kapasitesi Kontrolleri}

Betonarme taşıyıcı sistem elemanlarının (kolon, kiriş ve perde) gevrek (ani) olarak hasar görebilme kontrolleri, TS-500 yönetmeliğinde yer alan kurallara göre kesme kuvveti kapasiteleri hesaplanarak yapılır. Analizlerden elde edilen kesme kuvveti istemleri ile yönetmelik kurallarına göre hesaplanan kesme kuvveti kapasiteleri karşılaştırılmıştır. Ayrıca, betonarme kolon-kiriş birleşimlerinde kesme kuvveti dayanımı Türk Deprem Yönetmeliğinde verilen kurallara göre hesaplanmış ve kesme kuvveti istemi değerleri ile kontrol edilmiştir. Tablo 5'de binadaki bazı kiriş ve kolon elemanları ve Tablo 6'da 2 adet kolonkiriş birleşim bölgesi için kesme kuvveti karşılaştırmaları gösterilmiştir. Kesme kuvveti kapasitesi kesme kuvveti ihtiyacından daha az 
olan betonarme elemanlar gevrek olarak hasar gören elemanlar olarak tanımlanır ve göçme bölgesinde oldukları kabul edilir (DBYBH, 2007). İncelenen bina için yapılan kesme kontrollerinde gevrek kırılmaya maruz kalan herhangi bir taşıyıcı eleman tespit edilmemiştir.

\section{Betonarme Bina Sismik Performans Düzeyinin Belirlenmesi}

Türk deprem yönetmeliğinde, bina ve bina türü yapıların depreme karşı performans düzeyleri yapılara uygulanan deprem yükleri etkisinde yapıda meydana gelecek hasarların durumuna göre tanımlanmıştır. Deprem Yönetmeliğinde tanımlanan performans düzeyleri dört kısımdan oluşmaktadır. Uygulanan deprem analizleri sonucunda taşıyıcı elemanların yukarıda tanımlanan kesit hasar bölgelerinden hangisine ait olduğu belirlenir ve yönetmelikte her bir performans düzeyi için verilen şartlar dikkate alınarak binanın deprem performans düzeyi belirlenir.

Tablo 5. Kiriş ve kolonlar için kesme kuvvetleri

\begin{tabular}{|c|c|c|c|c|c|c|c|}
\hline $\begin{array}{c}\text { Eleman } \\
\text { Tipi }\end{array}$ & $\begin{array}{c}\text { Kesit } \\
\text { Boyutları }\end{array}$ & $\mathbf{V c}(\mathbf{k N})$ & Vs (kN) & Vt $(\mathbf{k N})$ & $\mathbf{V}(\mathbf{k n})$ & Durum & Sonuç \\
\hline Kiriş & K20x60 & 70.51 & 30.3 & 100.81 & 40.24 & $\mathrm{Vt}>\mathrm{V}$ & $\sqrt{ }$ \\
\hline Kiriş & K30x60 & 105.71 & 63.47 & 169.18 & 67.89 & $\mathrm{Vt}>\mathrm{V}$ & $\sqrt{ }$ \\
\hline Kolon & S25x50 & 89.98 & 51.3 & 141.28 & 51.3 & $\mathrm{Vt}>\mathrm{V}$ & $\sqrt{ }$ \\
\hline Kolon & S50x25 & 88.64 & 23.66 & 112.3 & 100.28 & $\mathrm{Vt}>\mathrm{V}$ & $\sqrt{ }$ \\
\hline Kolon & S60x30 & 137.54 & 29.19 & 166.73 & 247.09 & $\mathrm{Vt}<\mathrm{V}$ & $\mathrm{X}$ \\
\hline
\end{tabular}

Tablo 6. Kolon-kiriş birleşim bölgeleri kesme kuvvetleri

\begin{tabular}{|c|c|c|c|c|c|}
\hline Kolon Boyutu & Kiriş Boyutu & Ve $(\mathbf{k N})$ & V(kn) & Durum & Sonuç \\
\hline S25x40 & K30x60 & 384.92 & 315 & Ve $>V$ & $X$ \\
\hline S40x25 & K30x60 & 5.25 & 315 & $V e<V$ & $\sqrt{ }$ \\
\hline
\end{tabular}

\subsection{Kirişlerin Performans Düzeyinin Belirlenmesi}

Yönetmelikteki kurallara göre, yapının Hemen Kullanım Performans Düzeyinde olabilmesi için yapının herhangi bir katındaki kirişlerin en çok \%10’u 2. Bölge sınırlarında olabilir. Binanın 2. Bodrum Kat ve 1. Bodrum Kat kirişlerinde herhangi bir plastik şekil değiştirme oluşmadığından bu katların performans düzeyleri Hemen Kullanım Performans Düzeyi (HK) olarak kabul edilmiştir.

Can Güvenliği Performans Düzeyi’nde kirişlerin \%10'dan fazlasının 2. Bölgeye geçmesi fakat İleri Hasar Bölgesi'ndeki kirişlerin sayısının \%30'u geçmemesi gerekmektedir. $\mathrm{Bu}$ koşullara göre binanın Zemin Kat ve 2. Normal Katlarının Can Güvenliği (CG) Bölgesi'nde olduğu görülmektedir (Tablo 7).

Göçme Öncesi Performans Düzeyi'nde kirişlerin en fazla \%20'si 4. Bölgeye geçebilir. 1. Normal
Kat için yapılan hesaplarda kirişlerin \%20'sinin 4. Bölge'de olduğu saptanmıştır. $\mathrm{Bu}$ nedenle 1 . Normal Kat Göçme Öncesi Performans Düzeyi'ndedir (GÖ).

Binada herhangi bir kat Göçme Öncesi Performans Düzeyi şartlarını sağlayamıyorsa Göçme Durumu performans düzeyinde kabul edilir (DBYBH, 2007). Tablo 7'de görüldüğü gibi 3. Normal Kat'ta bulunan kirişlerin $\% 25$ 'i Göçme Bölgesi'ne geçmiştir ve GÖ performans düzeyini sağlamamaktadır. $\mathrm{Bu}$ sebeple 3. Normal Kat Göçme Durumu'ndadır.

Binadaki kirişlerin genel performans düzeyinin belirlenmesi için en uygunsuz koşula bakılmalıdır. İncelenen binada Kocaeli depremi ile yapilan doğrusal olmayan dinamik analizde elde edilen en elverişsiz durum 3. Normal Kat için tespit edilen Göçme Durumu'dur. Kiriş performansları bakımından bina Göçme Durumu'ndadır (Tablo 7). 
Tablo 7. Kirişler için performans değerlendirmesi

\begin{tabular}{|l|c|l|l|l|l|c|}
\hline Kat & Kiriş Sayıs & 1. Bölge & 2. Bölge & 3. Bölge & 4. Bölge & Sonuç \\
\hline 2. Bodrum Kat & 3 & $0 \%$ & $0 \%$ & $0 \%$ & $0 \%$ & HK \\
\hline 1. Bodrum Kat & 8 & $0 \%$ & $0 \%$ & $0 \%$ & $0 \%$ & HK \\
\hline Zemin Kat & 24 & $0 \%$ & $33 \%$ & $4 \%$ & $4 \%$ & CG \\
\hline 1. Normal Kat & 20 & $0 \%$ & $20 \%$ & $0 \%$ & $20 \%$ & Gö \\
\hline 2. Normal Kat & 20 & $0 \%$ & $40 \%$ & $5 \%$ & $10 \%$ & CG \\
\hline 3. Normal Kat & 20 & $0 \%$ & $25 \%$ & $0 \%$ & $25 \%$ & Göçme Durumu \\
\hline
\end{tabular}

\subsection{Kolonların Performans Düzeyinin Belirlenmesi}

Kolon elemanların kesit hasar seviyeleri belirlenirken kiriş elemanlarda olduğu gibi beton ve donatı çeliğindeki birim şekil değiştirme değerleri yönetmelikte verilen üst sinırlar ile karşılaştırılır. Katlara göre performans seviyesi kiriş elemanlarda tanımlandığı gibi yönetmelikteki HK, CG, GÖ ve Göçme Durumu kurallarına bağlı olarak elde edilir. 1. Bodrum Kat ve 2. Bodrum Kat'ta herhangi bir kolonda plastik hasar meydana gelmediğinden bu katlar Hemen Kullanım (HK) Performans Düzeyi'nde kabul edilmiştir (Tablo $8)$.

Can Güvenliği Performans Düzeyi için 3. Bölge'deki kolonların, her bir katta kolonlar tarafindan taşınan kesme kuvvetine toplam katkısı \%20'yi geçmemelidir. Diğer yapısal elemanlar 1. veya 2. Bölge'de olabilirler. Fakat, 1. Bölge'de bulunan kolonların kesme kuvvetine katkıs1 \%30'u aşmaması gerekmektedir. Bu koșulları sağlayan 1. Normal Kat Can Güvenliği (CG) Performans Düzeyi'nde olduğu tespit edilmiştir.

İleri Hasar Bölgesi'nde bulunan hiç kolon olmadığ1 ve Minimum Hasar Bölgesi'ndeki kolonların kesme kuvvetine toplam katk1s1 \%30'u geçmediğinden binanın 2. Normal Kat'1 Hemen
Kullanım (HK) Performans Düzeyi'nde kabul edilmiştir.

Göçme Öncesi Performans Düzeyi şartlarının kolon elemanlar için belirlenen ayrıntıları DBYBHY'de (2007) verilmiştir. Bu şartları sağlayan 3. Normal Kat'ın Göçme Öncesi Performans Düzeyi'nde olduğuna karar verilmiştir (Tablo 8). Ayrıca, Zemin Kat'ta 3. Bölge'deki kolonların katkısı $\% 20$ oranını aşmıştır bu nedenle bu katın performans düzeyi Göçme Öncesi Performans Düzeyi olarak tespit edilmiştir.

Binadaki tüm kolonlar için genel performans düzeyi en uygunsuz koşul dikkate alınarak tespit edilmelidir. Buradaki en uygunsuz durum Zemin Kat ve 3. Normal Kat için tespit edilen Göçme Öncesi Performans Düzeyi'dir. Bina kolon performansları bakımından irdelendiğinde Göçme Öncesi Performans Düzeyi'nde olduğu görülmüştür.

\section{Sonuçlar}

Bu çalışmada, kentsel dönüşüm kapsamında 1995 yılında inşa edilmiş betonarme bir binanın deprem performansı incelenmiştir. Binaya ait projeler ve deneysel yollarla elde edilen malzeme özellikleri kullanılarak binanın üç boyutlu sonlu elemanlar modeli kurulmuştur.

Tablo 8. Kolonlar için performans değerlendirmesi

\begin{tabular}{|l|c|c|c|c|c|}
\hline Kat & 1. Bölge & 2. Bölge & 3. Bölge & 4. Bölge & Sonuç \\
\hline 2. Bodrum Kat & $0 \%$ & $0 \%$ & $0 \%$ & $0 \%$ & HK \\
\hline 1. Bodrum Kat & $0 \%$ & $0 \%$ & $0 \%$ & $0 \%$ & HK \\
\hline Zemin Kat & $27.5 \%$ & $37.5 \%$ & $35.8 \%$ & $0 \%$ & Gö \\
\hline 1. Normal Kat & $8.3 \%$ & $60.3 \%$ & $7.0 \%$ & $0 \%$ & CG \\
\hline 2. Normal Kat & $20.2 \%$ & $45.5 \%$ & $0 \%$ & $0 \%$ & HK \\
\hline 3. Normal Kat & $31.5 \%$ & $50.2 \%$ & $0 \%$ & $10.5 \%$ & Gö \\
\hline
\end{tabular}


Doğrusal Olmayan Zaman Tanım Alanında analizler uygulanarak DBYBHY'de (2007) tanımlanan kurallar esas alınarak betonarme taşıyıcı elemanların kesit düzeyinde performansına karar verilmiştir.

Kirişler ve kolonlar için ayrı ayrı yapılan performans değerlendirmesi sonucunda her iki durum için en elverişsiz koşullar göz önünde bulundurulmuştur. Kirişler için belirlenen performans düzeylerine göre bina Göçme Durumu Performans Düzeyi'nde iken kolonlar için belirlenen performans düzeylerine göre bina Göçme Öncesi Performans Düzeyi'ndedir. Binanın deprem performansinın tüm bu elemanlarda oluşan hasar seviyelerinin en uygunsuz olanına göre belirlenmesi gerektiğinden incelenen binanın Göçme Durumu'nda olduğu belirlenmiştir. Binanın kullanımı can güvenliği bakımından sakıncalı olup yıkılıp yeniden inşa edilmesi gerekmektedir.

\section{Kaynaklar}

Adalier, K. ve Aydingun, O., 2001. Structural engineering aspects of the June 27, 1998 Adana-Ceyhan (Turkey) Earthquake. Engineering Structures, 23(4), 343-355.

Atmaca, M., 2013. Betonarme Yapılarda Performans Analizi. Yüksek Lisans Tezi, Eskişehir Osmangazi Üniversitesi Fen Bilimleri Enstitüsü. Eskişehir, 139s.

Caymazer, D., 2017. Kentsel Dönüşüm Kapsamındaki Betonarme Binaların Performanslarının Doğrusal Elastik Olmayan Hesap Yöntemiyle Belirlenmesi. Yüksek Lisans Tezi, Yıldız Teknik Üniversitesi Fen Bilimleri Enstitüsü. İstanbul, 137s.

Chopra, A. K., 2004. Estimating Seismic Demands for Performance-Based Engineering of Buildings. 13th World Conference Earthquake Engineering, Vancouver, Canada, Keynote Paper No. 5007.

City of Memphis and Shelby County, 2005. Appendix L.-Alternate seismic protection calculations and procedures. Memphis and Shelby County 2005 Joint Building Code Local Amendments, Memphis, Tennessee, USA.

CSI, SAP2000 V-15, 2015. Integrated Finite Element Analysis and Design of Structures,
Computers and Structures. Inc., Berkeley, California, USA.

DBYBHY, 2007. Deprem Bölgelerinde Yapılacak Yapılar Hakkında Yönetmelik. Bayındırlık ve İskan Bakanlığı, Ankara, Türkiye.

Duan, H. ve Hueste, M. B., 2012. Seismic performance of a reinforced concrete frame building in China. Engineering Structures, 41, 77-89.

Federal Emergency Management Agency, FEMA440, 2005. Improvement of Nonlinear Static Seismic Analysis Procedures. Washington, USA.

International Code Council (ICC), 2003. International Building Code", IBC 2003, False Church, Virginia, USA.

Kalkan, E. ve Kunnath, S. K., 2007. Assessment of current nonlinear static procedures for seismic evaluation of buildings. Engineering Structures, 29(3), 305-316.

Karabulut, A., 2011. TDY 2007 Yönetmeliği ve FEMA 440 Raporunda Tanımlanan Doğrusal Olmayan Analiz Yöntemlerinin Mevcut Betonarme Binalar İçin Karşılaştırılması. Yüksek Lisans Tezi, İstanbul Teknik Üniversitesi Fen Bilimleri Enstitüsü. İstanbul, 331s.

Kueht, E. ve Hueste, M. D., 2009. Impact of code requirements in the Central United States: seismic performance assessment of a reinforced concrete building. ASCE Journal of Structural Engineering, 135(4), 404-413.

Mander, J. B., Priestley, M. J. N., ve Park, R., 1988. Theoretical stress-strain confined concrete. Journal of Structural Division (ASCE), 114(8), 1804-1826.

MATLAB 6.1, The MathWorks Inc., Natick, MA, 2000.

Pinho R. ve Antoniou, S., 2005. A DisplacementBased Adaptive Pushover Algorithm for assessment of vertically irregular frames. Proceedings of Fourth European Workshop on the Seismic Behavior of Irregular and Complex Structures, Thessaloniki, Greece.

Poursha, M. K., 2008. A consecutive Modal Pushover Procedure for estimating the 
seismic demands of tall buildings. Engineering Structures, 31, 591-599.

Sadjadi, R., Kianoush, M. R. ve Talebi, S., 2007. Seismic performance of reinforced concrete moment resisting frames. Engineering Structures, 29(9), 2365-2380.

Scawthorn, C. ve Johnson, G. S., 2000. Preliminary report: Kocaeli (Izmit) Earthquake of 17 August 1999. Engineering Structures, 22(7), 727-745.

Sezen, H., Whittaker, A. S., Elwood, K. J. ve Mosalam, K. M., 2003. Performance of reinforced concrete buildings during the August 17, 1999 Kocaeli, Turkey Earthquake, and seismic design and construction practice in Turkey. Engineering Structures, 25 (1), 103-114.

Southern Building Code Congress International (SBCCI), 1999. Standard Building Code
(SBC). Southern Building Code Congress International, Birmingham, Alabama, USA.

Şahin, B., 2010. Depremde Bina Performansının Doğrusal Elastik Olmayan Yöntemler İle Belirlenmesi ve Yöntemlerin Sonuçlarının Karşılaştırılması. Yüksek Lisans Tezi, Yıldız Teknik Üniversitesi Fen Bilimleri Enstitüsü. İstanbul, 122s.

TS-500, Betonarme Yapıların Tasarım ve Yapım Kuralları. Türk Standartları Enstitüsü, Ankara, 2000.

XTRACT v.3.0.8, 2004. Cross-Sectional Structural Analysis of Components, Imbsen Software systems, 9912 Business Park Drive, Suite 130 Sacramento, CA 95827.

6306 Sayılı Afet Riski Altındaki Alanların Dönüştürülmesi Hakkında Kanun, R.G: 31/05/2012-28309. 